\title{
Representation of inflected signs from American Sign Language in short-term memory
}

\author{
HOWARD POIZNER, DON NEWKIRK, and URSULA BELLUGI \\ Salk Institute for Biological Studies, La Jolla, California 92037 \\ and \\ EDWARD S. KLIMA \\ Salk Institute for Biological Studies, La Jolla, California 92037 \\ and University of California at San Diego, La Jolla, California 92037
}

\begin{abstract}
In order to help illuminate general ways in which language users process inflected items, two groups of native signers of American Sign Language (ASL) were asked to recall lists of inflected and uninflected signs. Despite the simultaneous production of base and inflection in ASL, subjects transposed inflections across base forms, recalling the base forms in the correct serial positions, or transposed base forms, recalling the inflections in the correct serial positions. These rearrangements of morphological components within lists occurred significantly more often than did rearrangements of whole forms (base plus inflection). These and other patterns of errors converged to suggest that ASL signers remembered inflected signs componentially in terms of a base and an inflection, much as the available evidence suggests is true for users of spoken language. Componential processing of regularly inflected forms would thus seem to be independent of particular transmission systems and of particular mechanisms for combining lexical and inflectional material.
\end{abstract}

American Sign Language (ASL) is the visual-gestural language of the deaf communities in the United States. Since ASL utilizes a sensory modality different from that of spoken languages, its study provides an unusual opportunity for insight into the nature of language processing. As a visual language, ASL makes use of dimensions of space and movement to form both basic lexical items (signs) and grammatically inflected forms (forms with added grammatical markers for such attributes as person, aspect, and number). Whereas spoken languages characteristically rely on the sequential organization of sound segments to form words, ASL tends to organize its structural information simultaneously. We examine in the present article how signers encode one aspect of ASL in short-term memory, that of grammatically inflected signs.

This work was supported in part by National Institutes of Health Grant R01 HD 13249 and Grant NS15175 and by National Science Foundation Grant BNS 79-16423 to The Salk Institute for Biological Studies. Portions of this paper were presented at the Second Annual National Symposium on Sign Language Research and Teaching, San Diego, California, October 1978. We thank Dr. Elissa Newport, Venita Lutes-Driscoll, and Malinda Williams for their help throughout this project. We would also like to thank the people who graciously served as subjects and Dr. Ray Jones, Dr. Harry Murphy, Sharon Carter, and Dennis Schemenauer of the California State University at Northridge for their assistance and for allowing us to use their facilities for the experiment. All the illustrations were drawn by Frank A. Paul.
This issue is an important one because it not only relates to storage processes in the deaf for a visualgestural language, but also because it provides a strong test of alternate models of how language users in general represent inflected items in memory. The inflected English word "walking," for example, consists of two meaningful units, the verb "walk" and the inflection for progressive aspect "-ing." Representation of such an inflected item in memory could take one of at least two forms. For one, morphological components could be stored together as a single distinct and inseparable semantic unit. Alternatively, the verb stem and the inflection could be separately encoded, with their combination determined by morphological rule.

Studies of the processing of inflected English words have generally favored the second account. Gibson and Guinet (1971), for example, found that inflectional endings were indeed perceived as units in the tachistoscopic presentation of words and pseudowords. There were fewer errors on inflectional endings than on noninflectional endings of the same length; subjects added inflections to words presented as base forms, deleted inflections from presented inflected forms, and substituted one inflection for another. Similarly, MacKay (1976) found that both production times and errors that subjects made in rapidly changing the tense of a verb were consistent with subjects' applying derivational rules to verb stems, and not consistent with a model that treated inflected verbs as unanalyzed forms. 
Murrell and Morton (1974) evaluated the effect of prior learning of words on the tachistoscopic recognition of related words and found a facilitating effect for learning morphemes but not for learning words similar in visual and phonetic form. In a similar vein, Stanners, Neiser, Hernon, and Hall (1979) evaluated the effect of prior presentation of words on the speed with which subjects decided whether a given letter string was a word. They found that only words differing in a regular inflection facilitated the lexical decision task to the extent obtained by repetition of identical words. Apparently, processing regularly inflected English verbs involves separately encoding the verb stem and the inflection.

Garrett (1975), and MacKay (1979) provide evidence for the separate encoding of basic English (and German) words and inflections from spontaneous errors of speech production. Garrett (1975), for example, observed morphological strandings, such as "It just sounded to start." In this stranding, the basic lexical items "start" and "sound" are switched in the sentence, with the inflection removed from "start" and reattached to "sound." MacKay (1979), furthermore, observed that when a verb was misplaced in a sentence, its stem underwent changes in inflection appropriate to its new syntactic position, rather than being misplaced as a fully integrated form.

Finally, Van Der Molen and Morton (1979) showed that English-speaking subjects separately code plural markers and root nouns in the immediate serial recall of lists of visually presented words. They furthermore indicated that the plural was sometimes coded in a way that did not distinguish among the various forms of the plural morpheme.

Thus, we have evidence that English speakers decompose inflected words in a variety of processing tasks. ASL morphology, however, differs from English morphology in an important aspect: Inflectional processes in ASL impose simultaneous changes in, rather than sequential additions to, basic lexical items. Evaluating processing of ASL inflections, therefore, can provide a potentially stronger test of a general decomposition process during the encoding of inflected items. Such evaluation can also provide evidence for the psychological reality of an inflectional system in ASL, adding data from language processing to the structural and distributional evidence of the linguistic analysis. A brief description of ASL follows to set the stage for the present experiment.

ASL is the native language of most deaf children of deaf parents in the United States and is unrelated to English or to any other spoken language, having its own lexicon, rules of sign formation, and grammar (see Klima \& Bellugi, 1979). ${ }^{1}$

The internal structure of signs in ASL can be described in terms of three major formational parameters: configuration of the hands, movement of the hands and arms, and location of the hands relative to the body
(Klima \& Bellugi, 1979; Stokoe, Casterline, \& Croneberg, 1965). Discrete values along these linguistic dimensions are combined simultaneously but function separately to contrast minimally different signs. The sign HOME, ${ }^{2}$ for example, is made with a cupped hand with the thumb touching the fingertips, first contacting the side of the chin and then contacting the cheek. This sign is differentiated from the sign YESTERDAY only by the configuration of the hand. For YESTERDAY the hand is arranged in a fist with the thumb extended, making the same double contact on the face. Other pairs of signs are similarly differentiated by contrasts within the other formational parameters.

The proposed formational parameters of signs not only describe linguistic structure, but also can account for the kinds of errors deaf signers make in memory tasks. Bellugi, Klima, and Siple (1975) and Bellugi and Siple (1974) have shown that in short-term memory tests for signs, a significant number of multiply occurring intrusion errors were of a formational rather than a semantic nature. These formational errors paralleled the phonologically based intrusion errors of hearing subjects in the immediate recall of lists of English words. Similarly, Poizner, Bellugi, and Tweney (in press) found that formational, but not semantic, similarity of signs markedly interfered with the recall of sequences of signs, much as the acoustic similarity of words interferes with the recall of sequences of words. Newkirk, Klima, Pedersen, and Bellugi (1980) provide further evidence that signs are processed in terms of a limited set of essentially meaningless formational components. They found that signers interchanged individual formational values in errors occurring in spontaneous sign production, so-called slips of the hand. These transpositions of representatives of formational parameters most often resulted in gestures that were not actual ASL signs but were nevertheless composed of valid combinations of sign components.

The simultaneous organization of structural information in ASL extends beyond the basic lexical level. Recent linguistic research on the structure of ASL has led to the discovery of meaningful modifications of the basic signs-regular changes in the temporal-spatial contours of signs which regularly modulate their meanings (Bellugi, 1980; Fischer \& Gough, 1978; Klima \& Bellugi, 1979; Supalla \& Newport, 1978). We find that ASL exhibits a very rich set of inflectional variations on its lexical units. Such inflectional processes seem a favored form of semantic differentiation in the language, expressing many fine distinctions of meaning.

Thus ASL appears to differ dramatically from English and other spoken languages in the mechanisms by which its lexical units are modified. For the form of its morphological processes, the mode in which the language developed appears to make a crucial difference. Morphological processes in English and other spoken languages-the means by which complex words are built 
from minimal meaningful units-typically involve the linear addition of phonological segments to words. ASL has little tendency to build up its lexical units in this way. Rather, signs undergo a wide variety of morphological processes, each of which operates by imposing different dynamic changes in movement and spatial contouring. These regular modifications of signs represent a rich morphological system that makes structured use of the dimensions of the spatial mode, compacting a great deal of information systematically into single sign units. Movement information alone is sufficient for the identification of ASL inflections, as demonstrated by isolating movement from sign forms in presenting the forms as a few moving points of light (Poizner \& Bellugi, 1980; Poizner, Bellugi, \& Lutes-Driscoll, in press).

The experiment reported here is one of the first to deal with the coding and remembering of morphologically complex signs. Since ASL is a visual language and since its morphology organizes structural information simultaneously, signers unlike English speakers may indeed store inflected signs as distinct, holistic items. In fact, Newkirk et al. (1980) did not observe morphological strandings in spontaneous errors of sign production [although only about 131 attested slips of the hand were collected, a very small sample compared with the thousands of spoken language production errors collected by Garrett (1975)]. In the present study, we evaluated whether signers encode morphological components of inflected signs separately in a short-term memory task. If signers do decompose and store morphological components of inflected signs separately in memory, then, despite the difference in sensory modality and despite the simultaneous organization of ASL morphology, componential rather than holistic processing of inflected items would seem a general way in which language users process inflected forms. If such decomposition into morphological components does not occur, then the form of the morphology may determine the nature of the encoding process.

\section{METHOD}

\section{Subjects}

Two groups of native signers served as subjects. The first comprised eight congenitally deaf adults of deaf parents, who learned ASL as a first language and who currently use ASL as their primary mode of communication. The second comprised seven normal-hearing adults of deaf parents who also learned ASL as a first language and who currently teach ASL or work as professional interpreters.

\section{Stimuli}

Ten basic ASL verbs and eight inflected forms of each verb were used. The 10 verbs used were: LOOK-AT, PREACH, MOCK, BLAME, GIVE-A-GIFT, PAY, ASK, SHOOT, BEAT, TAKE-ADVANTAGE (see Figure 1). The eight inflections used were distinctly different and easily distinguishable in form. Two forms were inflections for referential indexing (first-person object, reciprocal), three for numerosity (multiple, exhaustive, dual), and three for temporal aspect (durational, iterative,

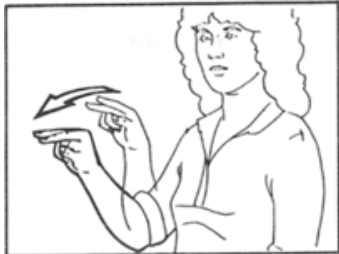

(a) LOOK-AT

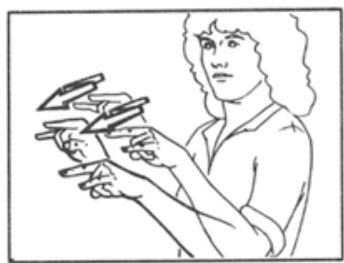

(c) MOCK

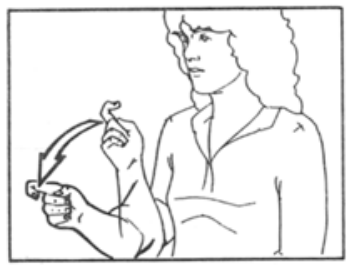

(e) GIVE-A-GIF T

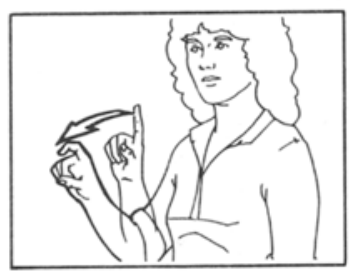

(g) ASK

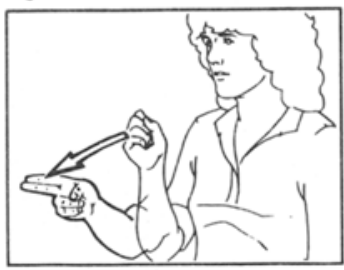

(i) BEAT

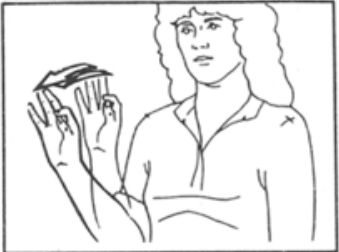

(b) PREACH

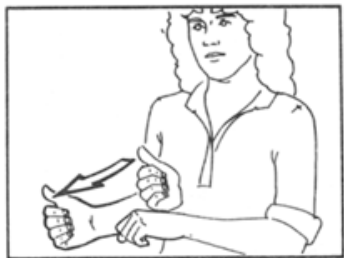

(d) BLAME

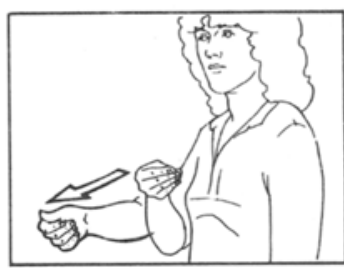

(f) PAY

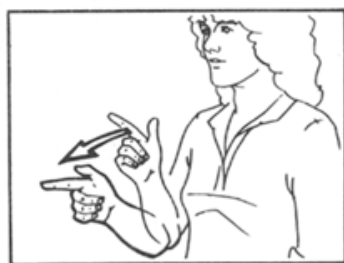

(h) SHOOT

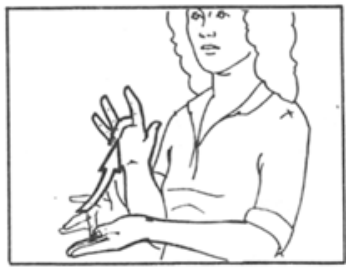

(j) TAKE-ADVANTAGE
Figure 1. The 10 basic signs used.

incessant). Figure 2 illustrates the basic sign PREACH and its form under the eight inflections used in this study. First-person object (2a) conveys the meaning "VERB me." Reciprocal (2b) indicates mutual action between two agents and conveys the meaning "VERB each other." Dual (2c) indicates action toward two objects, meaning "VERB the two of them." Multiple (2d) indicates plural (more than two), meaning "VERB them." Exhaustive (2e) indicates individuated action to each recipient, as in "VERB each one." The durational inflection (2f) indicates ongoing activity, and conveys the meaning "VERB continuously." The iterative inflection (2g) indicates action recurring over time, as in "VERB over and over again." The incessant inflection $(2 \mathrm{~h})$ indicates that the action referred to recurs so often that it seems it will never stop, as in "VERB incessantly." Note that ASL expresses a number of distinctions for coding the temporal contour of events, separating, for example, whether the event is continuous or recurring with breaks in time. (See Klima and Bellugi, 1979, for further discussions of these and other aspectual distinctions.) 


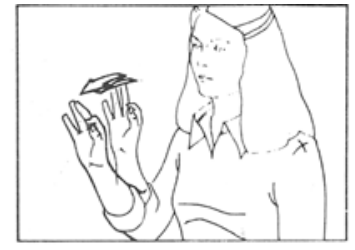

PREACH [UNINFLECTED]

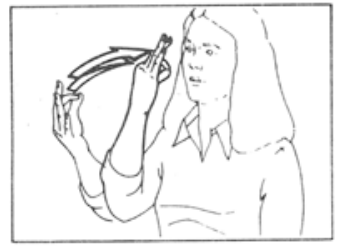

(a) PREACH [1st PERSON OBJECT] 'preach to me'

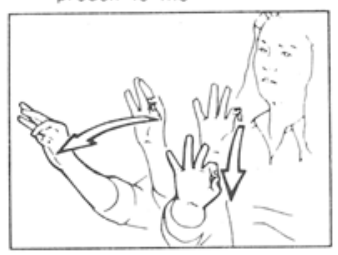

(c) PREACH [DUAL]

'preach to both

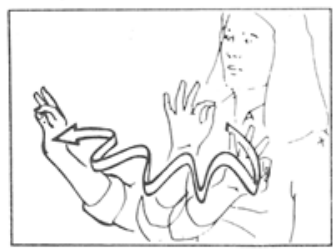

(e) PREACH [EXHAustive] 'preach to each'

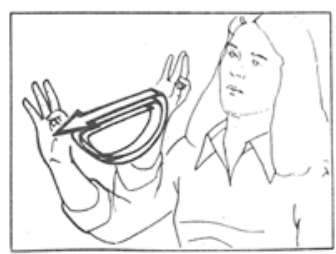

(g) PREACH [ITERATIVE]

preach over and over '

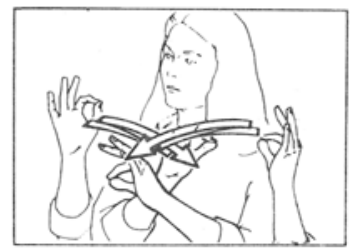

(b) PREACH [RECIPROCAL] preach to each other

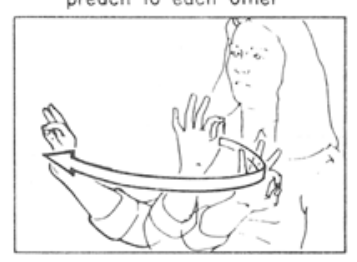

(d) PREACH [MULTIPLE] preach to them

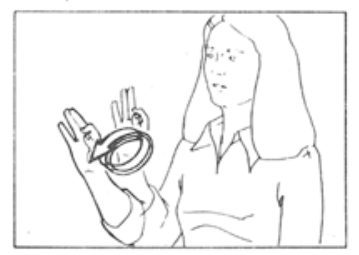

(f) PREACH [DURATIONAL] preach continuously

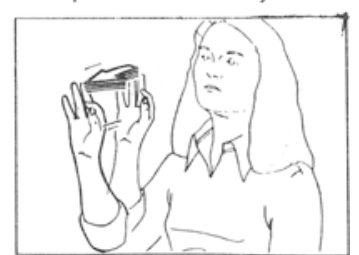

(h) PREACH [INCESSANT] 'preach incessantly'
Figure 2. The eight inflections used, shown here occurring with the basic sign PREACH.

\section{Apparatus and Procedure}

The 10 verbs were randomly paired with the eight inflections, each verb and each inflection appearing about equally often. We constructed three types of lists from the pool of inflected and uninflected signs. In the first list, two of the four signs were inflected; in the second, three were inflected (see Figure 3); and in the third, all four were inflected. Neither basic verbs nor inflections were repeated within a list. ${ }^{3}$

Each type of list was used 12 times in each of two blocks of 36 lists. Within each block, lists were randomly arranged. Each of the four possible positions for the uninflected signs in Type 2 lists was used three times, and each of the six positions of uninflected signs of Type 1 lists was used twice. Block 2 was created by putting the stimulus lists from Block 1 in a different order. Half the subjects received Block 1 before Block 2, and half received the reverse. A deaf native signer, paced by a flashing metronome (Seth Thomas, E962-000), produced each stimulus item at the rate of about one every $1-1 / 8 \mathrm{sec}$ with facial expression neutral. The stimulus lists were recorded on videotape (Sony, AV-3600), with a 15-sec gray interval separating lists. Immediately after viewing each list, subjects tried to recall, in sign, each item in the correct serial position. The responses of subjects were videotaped for later analysis.

Before viewing the experimental tape, subjects received 12 practice trials, with items sampled from those used in the experiment. The first six practice trials consisted of lists of three items each; the second six were of four items. Each verb and each inflection appeared about equally often in these lists. All instructions were presented in ASL on videotape. During the test session, subjects were given a short break after completing the first 36 trials.

In a separate check of the perceptibility of stimulus items, we asked two native signers to shadow one block of stimulus lists, that is, to copy the stimuli as they were being presented without having to recall them. Naturally, the rapid response requirements of shadowing and the memory load induced by any shadowing lag would lead to shadowing errors, as would any misperception of stimuli. Thus, if subjects can accurately shadow the stimulus lists, the individual stimulus items must be perceptible.

\section{RESULTS}

Two deaf ASL signers in our laboratory transcribed subjects' responses. ${ }^{4}$ Responses were counted as correct if the fully correct form (basic sign and inflection) was recalled in the correct serial position. Particular attention was paid to patterns of errors in recall, as discussed below.

The two subjects who shadowed the stimulus lists were highly accurate in their shadowing responses;

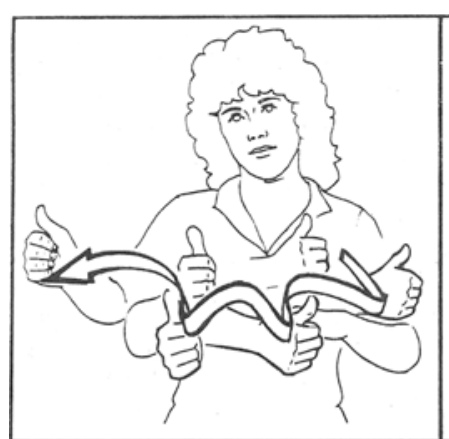

(a) Blame [exhaustive]

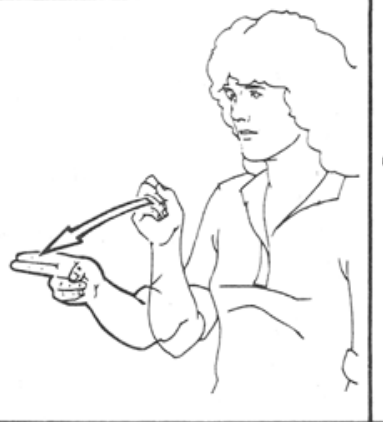

(b) BEAT [UNINFLECTED]

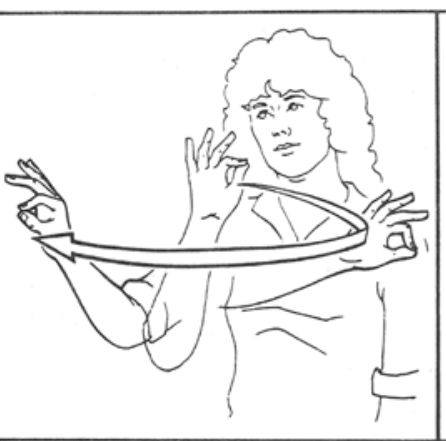

(c) PREACH [MULTIPLE]

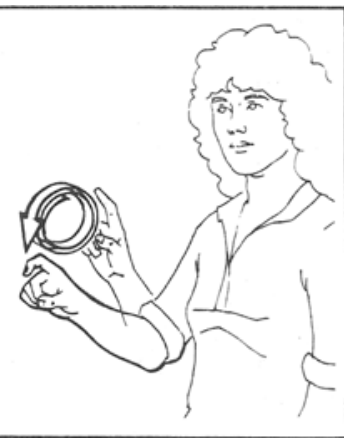

(d) ASK [DURATIONAL]

Figure 3. Stimulus list of Type 2. 
Table 1

Mean Percentage of Correct Responses and Standard Errors for Items From Each Type of List and Overall Accuracy for Each Group

\begin{tabular}{|c|c|c|c|c|c|c|c|}
\hline \multirow{3}{*}{$\begin{array}{l}\text { Subject } \\
\text { Group }\end{array}$} & \multicolumn{7}{|c|}{ List Type } \\
\hline & \multicolumn{2}{|c|}{1} & \multicolumn{2}{|c|}{2} & \multicolumn{2}{|c|}{3} & \multirow[b]{2}{*}{$\mathbf{P}$} \\
\hline & Mean & $\mathrm{SE}$ & Mean & $\mathrm{SE}$ & Mean & $\mathrm{SE}$ & \\
\hline Deaf Signers & 56.5 & 6.7 & 43.4 & 6.1 & 37.7 & 4.7 & 45.8 \\
\hline Hearing Signers & 50.5 & 3.4 & 36.3 & 2.8 & 27.1 & 2.4 & 38.0 \\
\hline
\end{tabular}

Note-List Type 1 = two inflected forms, two uninflected forms; List Type $2=$ three inflected forms, one uninflected form; List Type $3=$ four inflected forms; $P=$ pooled.

overall they were $94.8 \%$ correct. The few discrepancies that occurred were due primarily to the substitution of one highly similar inflection for another. For example, a shadowing "error" that occurred more than once was shadowing of the habitual inflection for the durational on a sign. The two inflections differ only in their end manner of movement; only one was used in this study. The accuracy in shadowing the stimuli $(94.8 \%)$ stands in sharp contrast to the accuracy with which the stimuli were recalled $(41.9 \%)$, indicating that memory errors were not simply failures to perceive the presented stimuli accurately.

Subjects were $41.9 \%$ correct overall in recalling items in their correct serial position. Table 1 presents the mean percentage of correct responses for items from each type of list and the overall accuracy for each group. We see that, for each group of signers, accuracy decreased in going from Type 1 lists to Type 3 lists, that is, as the number of morphological components in each type of list increased. A two-way mixed-design analysis of variance was performed on the accuracy with which subjects recalled items from each list type. Subject group (deaf, hearing) served as a between factor and list type served as a within factor. Neither the effect of subject group nor the Subject Group by List Type interaction was significant $[F(1,13)=1.52$, n.s., $F(2,26)=.57$, n.s., respectively], indicating that deaf signers and hearing signers differed reliably neither in overall accuracy nor in relative accuracy, depending on list type. The main effect of list type, however, was highly significant $[F(2,26)=45.9, \quad p<.001]$. Multiple comparisons revealed that recall for Type 1 lists was significantly higher than recall for Type 2 and 3 lists, but that Type 2 and 3 lists did not reliably differ (Tukey HSD test).

\section{Patterns of Errors}

We focus our analysis on patterns of errors. If subjects store inflection and base separately, they should in general forget and retain inflected forms in terms of morphological components, and taxing memory should lead to rearranging inflections and base forms in recall. We can evaluate the nature of the encoding of these stimuli by comparing presented stimuli with the recall of items in the same serial positions. Suppose, for example, that LOOK[durational] had been presented in Position Number 2 of a list and that ASK[reciprocal] had been presented in Position 4 of the same list. If in recalling the list a subject had responded with LOOK[reciprocal] in Position 2 and with ASK[durational] in Position 4, we would say that the inflections from the two forms had been transposed in recall, with the basic signs maintaining the correct serial positions. We expect such errors if subjects code inflected signs in terms of morphological components. If, however, the subject had recalled LOOK[durational] in Position 4 and ASK[reciprocal] in Position 2, entire forms would have been transposed in recall, much as we might expect if the unit of storage was the whole form. Table 2 presents the obtained percentages of occurrence of various error types of the total number of errors for both groups of subjects.

\section{Misorderings of Whole Items}

As the table indicates, whole items were misordered in only $6.1 \%$ of the errors. Indeed, misorderings of whole forms occurred with only one-third the frequency of errors of rearranging morphological components within lists $(18.2 \%)$, a difference in frequency of occurrence that is highly significant for both subject groups $\left(\mathrm{t}_{\text {correlated }}=11.6, \mathrm{p}<.001, \mathrm{t}_{\text {correlated }}=6.47, \mathrm{p}<.001\right.$, for deaf and hearing signers, respectively).

Table 2

Mean Percentage of Occurrence and Standard Errors of Various Error Types Out of the Total Number of Errors for Deaf and Hearing Signers

\begin{tabular}{|c|c|c|c|c|c|}
\hline \multirow[b]{3}{*}{ Error Category } & \multicolumn{5}{|c|}{ Percentage of Occurrence } \\
\hline & \multicolumn{2}{|c|}{ Deaf $(N=1,249)$} & \multicolumn{2}{|c|}{ Hearing $(N=1,252)$} & \multirow[b]{2}{*}{ Pooled } \\
\hline & Mean & SE & Mean & SE & \\
\hline Misorderings of whole items & 5.6 & 1.3 & 6.5 & .8 & 6.1 \\
\hline Exchanges of morphological components within lists & 19.4 & 1.6 & 17.0 & 1.6 & 18.2 \\
\hline Deletions of inflections & 10.1 & 1.7 & 15.1 & 2.5 & 12.6 \\
\hline Additions of inflections & 8.3 & 1.4 & 5.7 & .3 & 7.0 \\
\hline Intrusions & 34.9 & 4.3 & 29.2 & 2.5 & 32.1 \\
\hline Rearrangements of morphological components out of serial positions & 16.1 & 2.7 & 15.3 & 1.4 & 15.7 \\
\hline$x^{2}$ & 5.5 & .7 & 11.1 & 1.1 & 8.4 \\
\hline
\end{tabular}




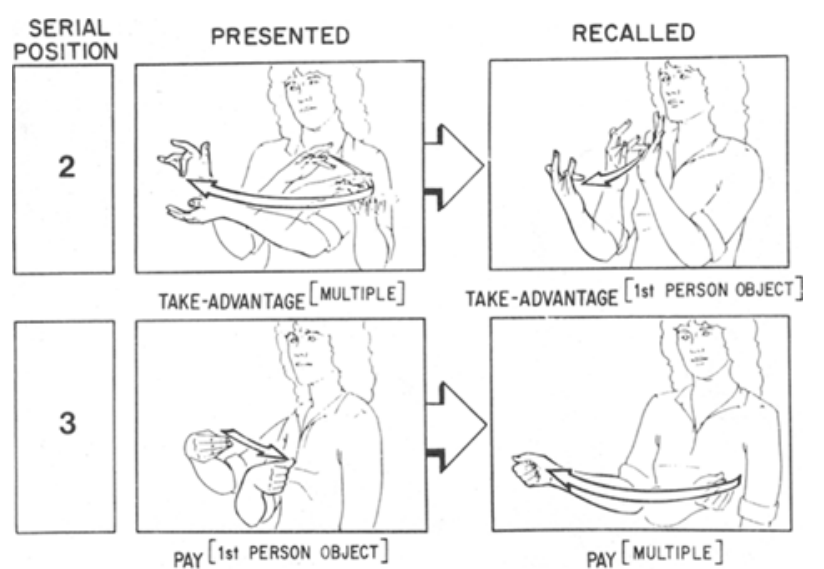

Figure 4. Exchanges of inflections within a list.

\section{Transpositions of Morphological Components}

Errors involving the rearrangement in recall of the morphological components of inflected forms, maintaining the correct serial position of one component or the other, amounted to $18.2 \%$ of all errors. (As with misorderings of whole items, exchanges of components did not have to be mutual to be tabulated as occurring.) To illustrate an error of this category, when TAKE. ADVANTAGE [multiple] and PAY[first-person object] were presented together in a list, a signer misrecalled TAKE-ADVANTAGE[first-person object] and PAY [multiple], respectively, having transposed the inflections in recall while leaving the basic signs in their correct serial positions (see Figure 4). In some errors, subjects transposed base forms while leaving the inflection in the correct serial positions. For instance, when BEAT [reciprocal] and SHOOT [multiple] were presented together in a list, a subject misrecalled SHOOT[reciprocal] and BEAT[multiple]. Interestingly, the frequency of basic signs being rearranged, with inflections maintaining correct serial positions, did not differ significantly from the frequency of inflections being rearranged with basic signs recalled in correct serial positions $\left(t_{\text {correlated }}=1.6, p<.05\right.$, for deaf and for hearing signers).

\section{Deletion or Addition of Inflections}

Subjects deleted inflections from inflected forms, recalling only the uninflected basic sign, in $12.6 \%$ of all errors and added inflections to signs presented in uninflected form in $7.0 \%$ of all errors. Inflections added to uninflected signs in recall that also occurred in the stimulus list are tabulated as additions of inflections to basic forms and not as rearrangements of morphological elements within lists.

\section{Other Types of Errors}

Of the types of errors remaining to be described, intrusion errors occurred most frequently (32.1\%). In these errors, some basic sign or inflection not pre- sented in the stimulus list appeared in the recall list. In another type of error, accounting for $15.7 \%$ of all errors, morphological components within a list were rearranged such that neither component of the recalled item appeared in the stimulus item in that serial position. In such cases, it is difficult to pinpoint exactly which stimulus the error was associated with, and, hence, it is difficult to evaluate precisely how the response was related to the stimulus presentation. Finally, the cate. gory "Other" listed in the last row of Table 2 includes errors of omission, errors of perseveration of whole items, and errors of misrecalling one uninflected sign for another. Such types of errors occurred relatively infrequently, totaling only about $8.4 \%$ of all errors obtained.

\section{Nestings}

Certain errors of rearranging morphological components occurred in which two inflections were combined together with a basic sign. For example, when BEAT[iterative] and ASK[first-person object] were presented in a stimulus list, one subject combined the two inflections from both presented forms with one of the basic signs, recalling BEAT[first-person object, iterative], meaning "beat me, over and over again." The form of the recalled item incorporated the directional movement toward the signer from the indexic inflection, as well as the cyclic, stressed, uneven thythm of the iterative inflection. Similarly, when the multiple and durational inflections were presented together in a list, a subject combined the two inflections together with a single basic sign in recall (see Figure 5). Although nestings of inflections were somewhat rare (they accounted for $2.5 \%$ of the errors for deaf signers and $1.2 \%$ of the errors for hearing signers), they provide an interesting source of evidence for the componential nature of the storage and retrieval of morphologically complex forms.

\section{EVIDENCE FOR ABSTRACT CODING}

Any sign form, inflected or uninflected, can be

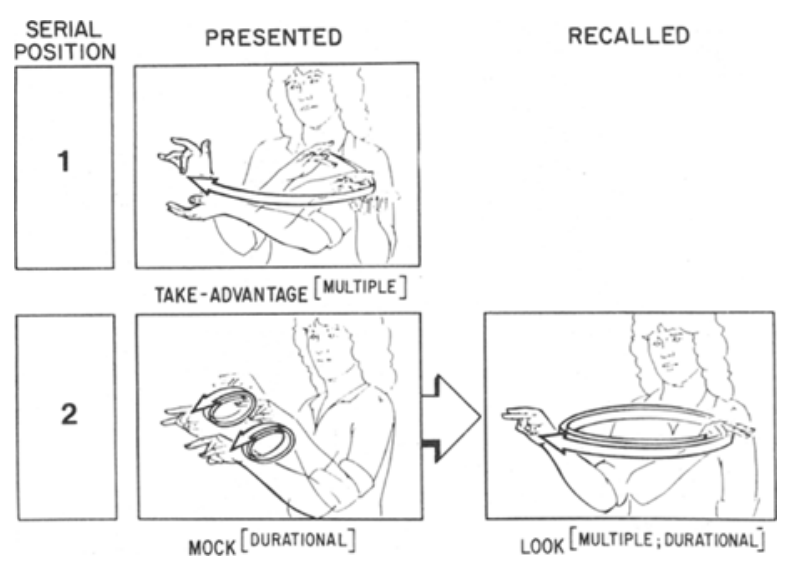

Figure 5. Nested inflections in recall. 
considered to consist of a combination of formational attributes. We want to evaluate the extent to which the errors subjects made in exchanging morphological components within lists can be accounted for simply on the basis of their misremembering movements similar in form. We address this issue in two ways. First, in ASL, the realization of an inflectional form may depend upon the properties of the sign stem that undergoes the inflection, much as in English, in which the plural inflection on nouns is realized variously as $/ \mathrm{s} /$ when the preceding sound is voiceless and as $/ \mathrm{z} /$ when the precedsound is voiced. When exchanges of morphological components occurred in which the forms of recalled inflections differed from those presented due to combination with different verbs, the coding of the inflections must have been morphologically based. Second, we estimate the likelihood that the observed item-and-error pairs occurred on the basis of similarity in form, and then evaluate whether the form of errors of exchanging morphological components within lists differs from that estimate.

Turning first to possible changes in the form of inflections in errors of exchanging morphological components, we note that the form of two inflections in particular depends upon which base form occurs with them. One inflection indicating that the object of the verb is first person is generally formed with the verb moving inward toward the signer's body, whereas the basic uninflected sign form moves away from the signer. In the case of TAKE-ADVANTAGE, however, the basic movement of the citation form is toward the signer [see Figure 1(j)], and thus the inflected TAKEADVANTAGE[first-person object] is directed away from the signer's body. Similarly, the inflection indicating reciprocal action has several formationally distinct forms: With some verbs (e.g., GIVE, ASK), the hands cross in front of the body; with others (e.g., LOOK-AT, SHOOT), the hands are oriented toward each other but do not cross; with still others (e.g., BLAME), one hand moves first to the left and then to the right.

The inclusion among our stimulus items of such inflections having variable forms made possible the occurrence of errors that could point to an abstract linguistic representation of inflections. Indeed, in misremembering combinations of basic signs and inflections, our subjects accommodated the form of the inflection to requirements of the basic sign. Because they did not encode these inflections strictly on the basis of surface form, it is likely that the rearrangement errors discussed earlier cannot be accounted for simply on the basis of subjects' misremembering movements similar in form. One example of this accommodation process is illustrated in Figure 6. When BLAME[multiple] and TAKEADVANTAGE[first-person object] were presented on the same stimulus list, a subject transposed the two inflections. The recalled items were thus BLAME[firstperson object] and TAKE-ADVANTAGE[multiple].

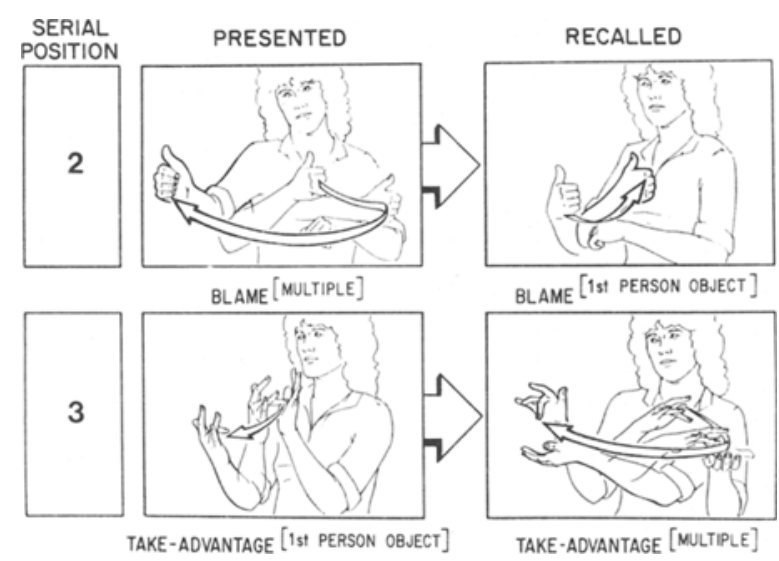

Figure 6. Exchanges of inflections within a list that incorporate a change in the form of an inflection.

Notice, however, that this rearrangement of inflections was not just a rearrangement of movement forms: When the sign TAKE-ADVANTAGE is inflected indexically for first-person object, the resulting movement is directed away from the body of the signer. However, when BLAME is inflected indexically to indicate firstperson object, the movement is directed toward the signer. Thus the signer correctly recalled the indexical inflection even though its form varied and even though a structurally well-formed sign [BLAME(uninflected)] would have resulted from combining the outward movement of the stimulus TAKE-ADVANTAGE[first-person object] with the verb BLAME. Storage of this inflection certainly involved more than remembering only the form of the movement.

Errors in rearranging another inflection, the reciprocal, also indicate that subjects did not encode inflections strictly on the basis of form but, rather, that subjects brought their linguistic knowledge of ASL to bear on the task. For example, when BEAT[reciprocal] and SHOOT[multiple] were presented together in a list, a subject rearranged the two basic signs, recalling SHOOT [reciprocal] and BEAT[multiple]. The form of the reciprocal inflection occurring with SHOOT differs from that occurring with BEAT. In the latter case the hands cross in front of the body. In the form of the reciprocal inflection occurring with SHOOT, however, the hands orient toward each other but do not cross (see Figure 7). Again we observe the correct recall of morphemes, but with the recalled inflection being appropriately different in form from the one presented.

A second line of evidence for abstract encoding of morphological components is based on an estimate of the likelihood that the observed item-and-error pairs of exchanges of morphological components occurred on the basis of similarity in movement form. This line of evidence also indicates that subjects were processing the stimuli morphologically. Just as an inflected sign can be analyzed as being composed of an inflection and a base, 


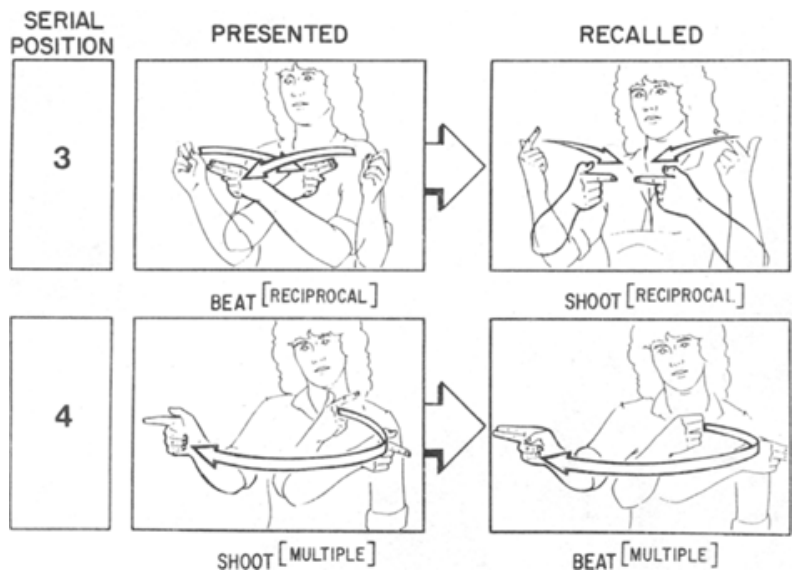

Figure 7. Exchanges of the basic signs of inflected forms, incorporating a change in the form of an inflection.

an inflection itself can be analyzed, not as a holistic unit but as a bundle of formational features. Such a descriptive feature system allows us to index the formational similarity of any pair of inflections and thus to evaluate the formational similarity of presented and recalled items. For example, the incessant inflection imposes a reduplicated movement on a shortened, tense verb stem. The multiple inflection, however, involves a single execution of the verb stem within a lateral sweep to the right. This movement differs from that for incessant on features of tension, displacement, and reduplication [see Figure $2(\mathrm{~d}$ and $\mathrm{h})$ ]. The two movements appear visually dissimilar. The exhaustive inflection, like the incessant, imposes a reduplicated movement on a shortened verb stem, but without lateral displacement of the movement and without added tension [see Figure $2(\mathrm{e})$ ] . The exhaustive and incessant inflections appear visually similar. Both are reduplicated, both shorten verb stems, neither has a circular contour, neither imposes two hands for the inflection, and so on. They differ primarily on features of tension and displacement. The multiple and the exhaustive inflections differ even more minimally on only one feature, reduplication. The Appendix presents a formational feature matrix describing and differentiating the movements of all inflected signs used as stimuli.

Previous studies of intrusion errors in short-term memory for signs (Bellugi, Klima, \& Siple, 1975; Klima \& Bellugi, 1979, chap.4) and for words and speech sounds (Conrad, 1964; Wickelgren, 1965a, 1965b, 1966) show that intrusion errors tend to be highly formationally based. Thus, the relative proportion of formationally similar to formationally dissimilar itemand-error intrusion pairs can serve as an estimate of the likelihood that a given error category occurred on the basis of subjects' misremembering movements similar in form. We will compare the relative proportion of formationally similar to formationally dissimilar item-and-error pairs for errors of exchanging morphological components with that for intrusion errors. The comparison determines whether the errors of exchanging morphological components can be accounted for simply on the basis of subjects' misremembering movements that were similar in form, based on the feature matrix in the Appendix.

In order to classify item-and-error pairs as formationally similar or dissimilar, a cutoff value was needed for the number of features separating two forms; pairs differing by fewer features than that value would be classified as formationally similar, whereas pairs differing by at least that number of features would be classified as formationally dissimilar. Although determination of a cutoff value must be somewhat arbitrary, we selected a value that appeared to reasonably specify visual similarity: Three or more features separating a pair of inflections indicated formational dissimilarity, whereas pairs separated by one or two features were classified as formationally similar. Pairs differing in the lexical stems used in this study were classified as formationally different.

Ratios of the frequency of occurrence of formationally similar to formationally dissimilar item-anderror pairs were calculated for intrusion errors and for errors of exchanging morphological components. Ratios of performance were used to normalize for the absolute number of errors in each category and for the absolute number of errors for each subject. The higher the ratio, the greater the proportion of formationally similar to formationally dissimilar item-and-error pairs. In fact, every subject but one had a higher ratio for intrusion errors than for errors of exchanging morphological components. The mean ratios for intrusion errors (.82, deaf signers; .74 , hearing signers) are significantly larger than the mean ratios for errors of exchanging morphological components (.24, deaf signers; .22 , hearing signers) for both groups of subjects ( $t_{\text {paired }}$ scores $=4.31$, $\mathrm{p}<.01, \mathrm{t}_{\mathrm{paired}}$ scores $=2.90, \mathrm{p}<.05$, for deaf and hearing signers, respectively). Thus, intrusion item-anderror pairs were more closely related formationally than were item-and-error pairs of exchanges of morphological components. This result indicates in yet another way that the errors of exchanging morphological components cannot be accounted for simply on the basis of subjects misremembering movements that happened to be similar in form. The result instead indicates that subjects were encoding inflected signs at a more abstract linguistic level.

\section{DISCUSSION}

Several lines of evidence converge to suggest that signers remembered inflected forms, not as holistic units but, rather, in terms of a base and an inflection. These results, in turn, provide evidence for the psychological reality of an inflectional system in ASL, adding data from language processing to the linguistic analysis of the system. First of all, the accuracy with which subjects recalled the stimulus lists decreased as the number of morphological components in the lists 
increased, much as we might expect if subjects coded inflected signs in terms of morphological components.

However, since inflected signs may differ from basic signs in attributes other than number of morphological components (i.e., in formational complexity and possibly in frequency of occurrence), analysis of accuracy to the various types of lists cannot bear directly on the question of separate storage of base and inflection; it is nonetheless reassuring that the pattern of accuracy for the various types of lists is consistent with such a coding of inflected forms. Clearly, a pattern of increased accuracy in recalling lists containing an increasing number of morphological components, rather than that obtained, would be difficult to reconcile with the independent storage of bases and inflections, inasmuch as it would require less storage capacity for inflected signs (as two-chunk units) than for basic signs (one-chunk units).

Much stronger evidence for the view that subjects encoded inflected signs componentially in terms of a base and an inflection comes from patterns of recall errors. The fact that subjects deleted inflections from inflected signs, recalling only the uninflected signs, and added inflections to signs presented in uninflected form suggests a separate encoding of basic sign and inflection. That these deletions and additions of inflections occurred despite any simple sequential suffix-like attachment of inflections to stems is one of several indications that subjects were not coding items solely in terms of form, but that they also brought their morphological knowledge of ASL to bear on the task.

Stronger evidence, yet, for a separate encoding of base and inflection comes from still other types of errors. If subjects store inflection and base separately, they should, in general, tend to correctly recall the morphological components of stimulus items, but should rearrange those components in recall into combinations different from those presented. Errors of recombining morphological components within lists occurred frequently, and indeed significantly more often than did errors of misordering whole forms (base plus inflection).

Several kinds of recombination errors are of particular interest. In one of them, two inflections were combined together with a basic sign in recall, even though no such doubly inflected forms occurred as stimulus items. Such elaborate layering of morphological components points both to a separate storage of base forms and inflections and to the highly combinatorial nature of ASL morphology. Strikingly, the form of the obtained item-and-error pairs for errors of exchanging morphological components differed reliably from an estimate of the likelihood that these errors occurred on the basis of similarity of movement form. Likewise, recombinations occurred in which the recalled inflection maintained the meaning but differed in form from the presented inflection. Thus, for example, when TAKEADVANTAGE[multiple] and PAY[first-person object] were presented together in a list, an error in recall was TAKE-ADVANTAGE[first-person object] and PAY [multiple]. Note that when the morphological operations are transposed, the first-person object inflection occurs with TAKE-ADVANTAGE rather than with PAY, but the movement path has switched direction (from movement toward signer to movement away from signer). This change in path is not due to the unpronounceability of TAKE-ADVANTAGE with movement toward signer, because in fact this path occurs in the basic uninflected form and in the form of the majority of verbs in ASL inflected for first-person object (not only for PAY but also for GIVE, INFORM, ASK, TELL, BLAME, and many other verbs). Thus the form is permitted, but not as the realization of that sign indexed for first-person object. Such rules may reflect a general principle in languages which Chomsky (1975) has called "structure dependency." This principle states that it is the internal structure of words and phrases and the nature of constituent parts rather than simply the sequence of elements that determines language regularities. Importantly, these parts are not directly mapped onto the signal; yet we see that a given path movement in ASL functions differently depending on its abstract linguistic nature. That such structure dependency occurs, not only in spoken languages but also in a visual-gestural language that tends to organize structural information simultaneously, indicates the possible universal status of this linguistic principle.

Since the same major patterns of recall errors appeared for hearing signers as for deaf signers in this study, data of the hearing signers (all of deaf parents) provide a replication of effects found for the deaf. We can therefore view these patterns of errors as highly reliable for native signers.

In addition, the deaf signers were slightly, although not significantly, more accurate than the hearing signers in correctly recalling stimulus items in the correct serial position. This result suggests that deaf signers probably would not have any gross sequential processing deficit in serial recall, despite the lack of auditory input. Evaluating sequential processing of deaf and hearing subjects to nonlinguistic stimuli, however, would certainly help further illuminate this issue.

All of the types of errors discussed in this section suggest that subjects were encoding inflections and base forms as independent units in a morphological system of a combinatorial nature. That such independent encoding of base and inflection occurred for forms in a visual language is intriguing because it suggests that short-term memory processes are atuned to linguistically significant components, be they spoken or signed. That such independent encoding occurred for ASL inflections is especially intriguing because lexical and grammatical information are simultaneously incorporated in ASL inflected forms. Thus, despite the simultaneous production of base and inflection and the visual nature of ASL, signers decompose and store these components separately in short-term memory. This componential processing of inflected items thus seems independent of particular languages and of particular transmission modalities. 
Appendix

Formational Feature Matrix Describing the Movement of the Stimulus Items

\begin{tabular}{|c|c|c|c|c|c|c|c|c|c|c|}
\hline & $\begin{array}{l}\text { Circling } \\
\text { Contour }\end{array}$ & $\begin{array}{l}\text { Tense } \\
\text { Stem }\end{array}$ & $\begin{array}{c}\text { Reduced } \\
\text { Stem } \\
\text { Movement } \\
\end{array}$ & $\begin{array}{c}\text { Redupli- } \\
\text { cated }\end{array}$ & Finite & $\begin{array}{c}\text { Two } \\
\text { Hands } \\
\text { Active } \\
\end{array}$ & $\begin{array}{c}\text { Contra- } \\
\text { lateral } \\
\text { Orientation }\end{array}$ & $\begin{array}{l}\text { Tan- } \\
\text { dem }\end{array}$ & $\begin{array}{l}\text { Retro- } \\
\text { grade }\end{array}$ & $\begin{array}{c}\text { Dis- } \\
\text { placed }\end{array}$ \\
\hline Uninflected Sign & - & - & - & - & -- & - & - & - & - & - \\
\hline Pr & - & - & - & + & - & - & - & - & - & - \\
\hline M & - & - & - & + & - & + & - & - & - & - \\
\hline First-Person Object & - & - & - & - & - & - & - & - & + & - \\
\hline $\operatorname{Pr}$ & - & - & - & + & - & - & - & - & + & - \\
\hline M & - & - & - & + & - & + & - & - & + & - \\
\hline Reciprocal & - & - & - & - & - & + & + & - & - & + \\
\hline $\mathrm{M}$ & - & - & - & + & - & + & + & - & - & + \\
\hline$A, B, G, P$ & - & - & - & - & - & + & + & + & - & + \\
\hline $\operatorname{Pr}$ & - & - & - & + & - & + & + & + & - & + \\
\hline $\mathrm{Bl}, \mathrm{TA}$ & - & - & + & + & + & - & + & - & - & + \\
\hline Dual & - & - & - & + & + & - & - & - & - & + \\
\hline $\mathbf{M}$ & - & - & - & + & + & + & - & - & - & + \\
\hline Multiple & - & - & + & - & - & - & - & - & - & + \\
\hline M & - & - & + & - & - & + & - & - & - & + \\
\hline Exhaustive & - & - & + & + & - & - & - & - & - & + \\
\hline $\mathrm{M}$ & - & - & + & + & - & + & - & - & - & + \\
\hline Durational & + & - & - & + & - & - & - & - & - & - \\
\hline $\mathbf{M}$ & + & - & - & + & - & + & - & - & - & - \\
\hline Iterative & - & + & - & + & - & - & - & - & - & - \\
\hline M & - & + & - & + & - & + & - & - & - & - \\
\hline Incessant & - & + & + & + & - & - & - & - & - & - \\
\hline $\mathbf{M}$ & - & + & + & + & - & + & - & - & - & - \\
\hline
\end{tabular}

Note-When the value of any feature of an inflected sign depends upon a particular verb stem, that form is listed separately under the inflection. Abbreviations for the different verb stems are as follows: $\operatorname{Pr}=P R E A C H, M=M O C K, L=L O O K, S=S H O O T, A=A S K$, $B=B E A T, G=G I F T, P=P A Y, B l=B L A M E, T A=T A K E \cdot A D V A N T A G E$.

\section{Description of Features}

The features we have used to describe the formation of the stimulus items refer specifically to surface forms and, with the exception of "retrograde motion," make no reference to processes that signs may have undergone to acquire such forms.

Circling contour indicates that path movement (i.e., movement of the whole hand through space) in a sign form has circular or elliptical shape.

Tense stem indicates that the inflected form is made with added tension, speed, and modified offset with respect to the basic uninflected form.

Reduced stem movement indicates that the inflected form is made with reduced path, reduction of size of local movement, and so on, with respect to the basic uninflected form.

Reduplicated indicates that the root movement of the sign is produced more than once in the execution of the sign form.

\section{REFERENCES}

Bellugi, U. The structuring of language: Clues from the structural similarities between signed and spoken language. In U. Bellugi \& M. Studdert-Kennedy (Eds.), Signed and spoken language: Biological constraints on linguistic form. Dahlem Konferenzen, Weinheim/Deerfield Beach-FL/Basel: Verlag. Chemie, 1980.

Bellugi, U., Klima, E. S., \& Siple, P. Remembering in signs. Cognition, 1975, 3, 93-125.

Bellugi, U., \& Siple, P. Remembering with and without words. In F. Bresson (Ed.), Current problems in psycholinguistics. Paris: Centre National de la Recherche Scientifique, 1974.

Chомsky, N. Reflections on language. New York: Pantheen Books, 1975.
Finite indicates that if the movement is reduplicated, exactly two sign movements appear.

Two hands active indicates that the movement of the sign form is produced independently by each of the signer's two hands in the course of executing the sign form.

Contralateral orientation indicates that the significant contracting region/focus of each active hand orients toward the contralateral side of the signer's body.

Tandem relation indicates that the two active hands are arranged such that the dominant hand is closer to the signer's body than is the nondominant hand in the execution of the sign form.

Retrograde motion indicates that the movement of the inflected form is produced in a direction opposite to that required in the basic uninflected form.

Displaced indicates that the path of movement is not in a sagittal plane.

Conrad, R. Acoustic confusions in immediate memory. British Journal of Psychology, 1964, 55, 75-84.

Fischer, S., \& Gough, B. Verbs in American Sign Language. Sign Language Studies, 1978, 18, 17-48.

Garrett, M. J. The analysis of speech production. Psychology of Learning and Motivation, 1975, 9, 133-177.

Gibson, E. J., \& Guinet, L. Perception of inflections in brief visual presentations of words. Journal of Verbal Learning and Verbal Behavior, 1971, 10, 182-189.

Klima, E. S., \& Bellvgi, U. The signs of language. Cambridge, Mass: Harvard University Press, 1979.

MACKAy, D. G. On the retrieval and lexical structure of verbs. Journal of Verbal Learning and Verbal Behavior, 1976, 15, 169-182.

MACKAY, D. G. Lexical insertion, inflection, and derivation: 
Creative processes in word production. Journal of Psycholinguistic Research, 1979, 8, 477-498.

Murrell, G. A., \& Morton, J. Word recognition and morphemic structure. Journal of Experimental Psychology, 1974, 102, 963-968.

Newkirk, D., Klima, E. S., Pedersen, C. C., \& Bellugi, U. Linguistic evidence from slips of the hand. In V. Fromkin (Ed.), Errors in linguistic performance: Slips of the tongue, ear, pen and hands. New York: Academic Press, 1980.

Poizner, H., \& Bellugi, U. Psycholinguistic studies of American Sign Language morphology. In B. Frokjaer-Jensen (Ed.), Selected Papers of the NATO ASI: Sign Language Research (Special Issue, LOGOS). Copenhagen: Audiologopedic Research Group, 1980.

Poizner, H., Bellugi, U., \& Lutes-Driscoll, V. Perception of American Sign Language in dynamic point-light displays. Journal of Experimental Psychology: Human Perception and Performance, in press.

Poizner, H., Bellugi, U., \& Tweney, R. D. Processing of formational, semantic, and iconic information of signs from American Sign Language. Journal of Experimental Psychology: Human Perception and Performance, in press.

Stanners, R. F., Neiser, J. J., Hernon, W. P., \& Hall, R. Memory representation for morphologically related words. Journal of Verbal Learning and Verbal Behavior, 1979, 18, 399-412.

Stokoe, W. C., Jr., Casterline, D., \& Croneberg, C. A dictionary of American Sign Language. Washington, D.C: Gallaudet College Press, 1965.

Supalla, T., \& Newport, E. How many seats in a chair? The derivation of nouns and verbs in American Sign Language. In $\mathrm{P}$. Siple (Ed.), Understanding language through sign language research. New York: Academic Press, 1978.

Van Der Molen, H., \& Morton, J. Remembering plurals: Unit of coding and form of coding during serial recall. Cognition, $1979,7,35-47$.

Wickelgren, W. A. Acoustic similarity and intrusion errors in short-term memory. Journal of Experimental Psychology, 1965, 70, 102-108. (a)

Wickelgren, W. A. Distinctive features and errors in shortterm memory for English vowels. Journal of the Acoustical Society of America, 1965, 38, 583-588. (b)

Wickelgren, W. A. Distinctive features and errors in shortterm memory for English consonants. Journal of the Acoustical Society of America, 1966, 39, 388-398.

\section{NOTES}

1. Several systems of manual communication exist in the United States which are based on English and which should not be confused with ASL. One such system assigns 26 distinct hand configurations to the letters of the English alphabet (fingerspelled English), with English words being manually spelled in the air letter by letter. Another system is organized around English at the phonetic level by assigning different gestures to different configurations of the vocal tract (cued speech, an adjunct to speech reading). Yet other manual systems use signs in English word order and add gestures for English affixes and functors (forms of signed English). Deaf people who are not very familiar with English, however, find manual systems based on English difficult to understand.

2. Lexical bases of signs are denoted by English glosses in full capitals (e.g., PAY). Multiword glosses for single-sign forms are hyphenated, as in GIVE-A-GIFT. Bracketed labels, as in PAY[dual], refer to specific inflectional processes signs have undergone.

3. One list in each block inadvertently contained the exhaustive inflection used on two verbs.

4. Responses of four subjects were independently transcribed by both deaf researchers. The transcriptions agreed highly $(90.8 \%)$.

(Received for publication May 1, 1980; revision accepted September 4,1980 .) 